\title{
TEACHING COMMUNICATION
}

\author{
Adrian Palmer \\ The University of Michigan
}

\begin{abstract}
A second-language teacher's classroom activity can be optimized by considering its relationship to the development, in his students, of communication skills. The development of these skills presupposes the presence and insights of a live teacher, and cannot be accomplished by a machine. That the techniques advocated here are practical, is illustrated by a description of communication practice (CP), as well as the following considerations: the introduction of new material, some aspects of course organization, and finally, the students' proper mental attitude toward language learning.
\end{abstract}

A language course has two components, the course content and the presentation of that content. 1 This paper deals with the presentation component. The main thesis is that classroom presentation should be directed from the outset toward the development of communication skills since the ultimate goal of language learning is communication. Although learning requires practice, this practice should be communication practice, not pattern practice. This theme will be developed in considering the following four topics:

I. The nature and form of communication practice drills.

II. The psychological preparation of the student to communicate.

III. The introduction of new content in communication practice.

IV. The relationship of communication practice to text and curriculum.

I. The nature and form of communication practice drills

In communication practice (CP) drills, the student finds pleassure in a response that is not only linguistically acceptable, but also conveys information personally relevant to himself and other people. The following two examples illustrate the form such drills might take and the rational basis for their use.

${ }^{1}$ I would like to thank the following people for reading this paper and offering many helpful suggestions: John Peterson, Laura Strowe, John Upshur, and Ronald Wardhaugh. 


\section{a. Example 1}

The most important aspect of a sentence is its meaning, not its form. Sentences can often be incorrect in formal respects but still convey the desired meanings, as in "I told him to opens the window." However, a formally correct sentence used in the wrong situation can lead to real-life problems, as with "I ordered the teacher to go open the window." Thus, sentences illustrating a new pattern should not be practiced without paying particular attention to their meanings. If the teacher discovers that his drills require only mechanical responses, then he should use some other technique to lead the student back into communication and away from pattern practice.

The most powerful technique at the teacher's disposal is his ability to verbally create situations which could be relevant to the student's own life and then to force the student to think about the meaning and consequences of what he would say in such situations. An example will make this clear. Let us say that the teacher wants to practice the following pattern:

\section{WOULD TELL HIM TO SHUT THE DOOR HER TURN ON THE LIGHT THEM BRING SOME FOOD}

He could proceed as follows:

1. Make sure the students understand the sentences, or if necessary, translate a representative sentence into the students' native language.

2. Point out the obvious facts about the structure of the sentence, such as:

a. WOULD + simple form of verb;

b. The object form of the pronouns HIM, HER, THEM;

c. TO + the simple form of the verb.

3. Have the students repeat two or three sentences from the pattern several times to make sure that they are making no gross mistakes such as saying "to shutting the door."

The next step is the most important one for the teacher. He must make his students feel that they are communicating an important idea when they use this pattern. One way to proceed is as follows: 
$\begin{array}{ll}\text { CAST: } & \text { Teacher } \\ & \text { Student-Paul } \\ & \text { Student-Karen } \\ & \text { Student-Susan }\end{array}$

TEACHER: "Karen, if you and Susan came to class at 8 a.m. and it was winter and the room was dark at 8 a.m., what would you tell Susan?"”

KAREN: (with any luck at all) "I would tell her to turn on the light."'

If Karen has trouble understanding the instructions, the teacher should repeat them, explaining the situation again or translating the original sentence. He must insure that Karen understands what she is replying to. If Karen answers correctly then the teacher turns to Paul:

TEACHER: "And how about you, Paul, if you were with Mary and you wanted to read, what would you do?"

PAUL: "I would tell her to turn on the light."

TEACHER: (in student's native language) " "You as a boy would tell a girl to do that for you?"

TEACHER: (continuing in the target language) "Paul, if you came alone, and if I was in the room, what would you do?"

This question is of a type which really forces the student to be imaginative. If he answers mechanically, he might say the following:

PAUL: "I would tell you to turn on the light."

At this point the teacher may react rather violently, accusing Paul of being impolite to a teacher and forcing him to see the implication of using the word tell in this pattern when addressing a superior. Or alternatively, the teacher might be more oblique and say:

TEACHER: "Then I would throw you out of class!"

This kind of a statement would make Paul and the other students

${ }^{2}$ The assumption here is that it might be difficult at this stage of instruction to explain the problem using the target language only. The implication of this is that the teacher should know the students' native language and use it whenever a point cannot adequately be made in the target language. This knowledge of the language will also make the teacher aware of its interference in second language learning. 
think about the reason for the teacher's statement and reach the conclusion that they should not tell a superior to do something. Let us see how communication practice and pattern practice (PP) drills differ. In theory, PP does involve a transfer of attention from form to meaning, but in reality the meanings of sentences grouped as they are in PP drills are not particularly relevant either to each other or to the students. His teacher and fellow students will react only if a student's response is grammatically incorrect. In giving correct responses, there is really no need for the student to consider more than superficial grammatical information. There is little or no sense of satisfaction in a correct response that is only grammatically acceptable but does not convey useful information.

In both communication practice and pattern practice drills, the student must be aware of the grammatical and semantic restrictions on the substituted lexical items. However in CP, the student would also pass judgment on the social acceptability of his utterance, and decide whether or not his utterance is a logical response to the situation. He would picture himself in a certain situation and consider those factors which influence what he would say outside of the classroom. He would consider his age, sex, and social status. He would worry about whether he is being polite or offensive. He would think about what the repercussions of a certain response would be. The inappropriateness of a student's remark is brought to his attention, as in the response: "I would throw you out of class!"

A further difference between the two types of drills is that while the PP drill can be administered by a machine such as a tape recorder, the CP drill cannot. Since communication drills require flexible and human responses (i.e. not flashing lights), then to administer such drills by machine appears impossible. A live teacher is absolutely necessary, and one is forced to conclude what few people really doubt anyway, that for certain tasks machines cannot replace humans. It follows that if communication drills are deemed sufficiently important, then the teacher should spend his classroom time in doing what he alone can do. His selfevaluation should include the following question: Could my role in teaching have been handled equally well by a machine? If the answer is "yes," the teacher can only conclude that he is wasting his talents.

\section{b. Example 2}

At a very early point in a language program it is advisable to bring the student's creative abilities into play. One way is as fol- 
lows: The teacher may require each student to prepare a few questions using vocabulary and grammar patterns in the last lesson that was studied. At the beginning of the course these questions will be very simple and short, and the answers will necessarily be equally brief. A simple dialogue, such as the following, can proceed using just a few key words and patterns. Paul has been asked to make up a question to ask in class:

CAST: Teacher, Paul, David, John, Mary, Bruce.

PAUL: "Who is taller, John or Mary?"

TEACHER: "Who are you asking?"

PAUL: "I'm asking David."

TEACHER: "Ask him again."

PAUL: "David, who is taller, John or Mary?"

TEACHER: "David, do you understand?"

DAVID: "Yes, I understand."

TEACHER: "Then answer the question."

DAVID: "John is taller than Mary."

TEACHER: "Mary, is David correct?"

MARY: "Yes, David is correct."

TEACHER: (speaking in student's native language) "How would you say what David just said?"

MARY: "John is taller than Mary."

TEACHER: (in student's native language) "Would you really say that, would you use your own name like that?" (Teacher translates Mary's inappropriate sentence into her native language.)

"Now try again."

MARY: "David is taller than I."

TEACHER: "Bruce, what did Mary say?"

BRUCE: "Mary said David is taller than she."

The key to this CP drill is flexibility and relevance to the classroom situation. Several responses are practiced by asking a single question of different people. Also, the question pattern which Paul wanted to practice is repeated in meaningful contexts. 
The teacher will have to explain why what a student is saying is incorrect. When there is no simple grammatical explanation then there is often an equally incorrect way of paraphrasing the student's sentence in his own language. Then the student will understand intuitively why he is wrong, and class time will not be wasted while the teacher gets involved in linguistics, semantics, or general confusion.

A variation on the above drill would be to require students to prepare short stories to be presented orally in class, using vocabulary and grammar patterns from past lessons that the students feel need extra practice. The teacher should encourage cleverness and the imaginative use of language even at the price of failing to achieve grammatical perfection. He should also listen with the goal of determining general weaknesses in intelligibility, to which he could then draw the attention of the entire class. The story can be immediately revised with all the students participating in the revision.

After the story has been revised and repeated by the student and retold by the teacher, then it should be discussed in the target language. In the early stages of instruction the discussion will be limited to simple questions about each sentence. Later on, however, the class can discuss the story in light of each student's own personal ideas: What would you do in that situation? Has such a thing ever happened to you? Could the story have been true? and so on. During the course there should be a conscious effort to transfer the responsibility for asking questions and leading discussions from the teacher to the students so that eventually a student will take over the leadership of the class for each discussion period. ${ }^{3}$

\section{The psychological preparation of the student to communicate}

A language teacher should instill in his students a number of skills which are more directly related to the students' psychological attitude toward new languages than their direct knowledge about the language. The importance of teaching these skills becomes obvious when one teaches by communication practice since effective communication requires their constant use.

\section{a. Skill in criticizing one's own performance}

To communicate effectively in a second language, one must be skilled in evaluating and criticising one's own speech. The

\footnotetext{
${ }^{3} \mathrm{~A}$ technique for transferring discussion leadership from teacher to student is described in Palmer (1968).
} 
teacher's role is more than one of providing a model for the student, calling attention to his mistakes, and teaching him how to correct them. A teacher should force the student to listen to himself as he speaks, to be able to recall what he has said, and to be able to pass judgment on his own correctness. The teacher must teach the student to become his own critic.

This goal is best achieved in stages. First, the students should be made to consider what other students are saying as a form of extended listening practice. Then, in evaluating each other, they would become aware of their own potential areas of difficulty, and eventually their own errors.

\section{b. Skill in understanding new or unexpected utterances}

Communication implies novelty. If all responses were predictable there would be no communication. Thus a student must be taught to take the proper attitude toward the unknown, both in understanding and production.

If a student hears a sentence which he does not understand he has three options: ignore it, ask what it means, or try and figure out its meaning. For the language learner, the third option is the most difficult to take, the second is easier but ultimately less productive, and the first must be avoided. The following is a technique for making the student take the third option.

When a student says, "I don't understand that sentence," the teacher must first decide whether he can realistically expect the student to understand. If he is not expecting too much, then the teacher must assess the student's past performance in class. If the student is one who frequently gives up on sentences which show even slight deviation from previously discussed patterns, then the teacher should conclude that the student has the wrong psychological approach to the new language. In this case he would be doing the student a disservice by directly explaining what the sentence in question means. The teacher has several options. He may repeat the sentence and say "Think about it," then remain silent. This approach is the "hard line" one and is often necessary with a more stubborn student who has the attitude that language learning is memorizing a set of sentences and using only those sentences. The first few times the student is told to "think about it" he might rebel. However he must not be given the answer. Rather, the teacher should pick out another student who does not completely understand either, but who the teacher knows is willing to guess. The teacher encourages this guessing and helps the student by suggesting different directions in which he might think in order to work out the meaning of the sentence. 
For example, if the language being taught is Thai, then the sentence under consideration might be one in which many objects and indirect objects are deleted leaving a string of verbs in a row. The student could be prodded into supplying the missing nouns by thinking about the context of the sentence, thus gradually relating the shortened sentence to a more easily understood complete version using details which are already known to the student. The class should be made to realize that meeting the challenge of new sentences in class is essential to developing conversational agility outside.

\section{c. Skill in expressing concepts}

In communicating, a student will often have ideas which he wishes to express in a second language, but cannot, because he lacks the imagination and initiative to try. Many times the teacher will realize that although the student's vocabulary background is sufficient he is afraid to deviate from sentences he has practiced, or words he has memorized. This situation often comes up when word-for-word translational equivalents do not exist between the student's native language and the target language. When a student balks at expressing a new concept, the teacher might simply say: "You already know these words $\mathrm{W}_{1} \mathrm{~W}_{2} \mathrm{~W}_{3}$, etc. Now think of a way you might put them together to express what you want to say." Then the student can struggle with the problem on his own and benefit from the teacher's evaluation of his efforts. He has been forced to take a big step in language learning, one which he will face repeatedly. He now opens his mind to the possibility of making intelligent guesses about how to express himself. His attitude toward language learning has changed.

As in the case of writing stories, students must learn to be innovative and imaginative in classroom conversation. In the classroom, unlike in a language laboratory, there is the unique opportunity for the student to be told whether his unexpected response was correct or appropriate.

Some students may have difficulty using language creatively. Often, however, the teacher can find something in the personality of the student which can be counted upon to evoke new responses. If the teacher realizes that a student has a particular tendency toward joking, he can "set him up" with a situation in which a simple joke would be a nice alternative to a routine answer. "The battle of the sexes" can often be used to set up situations in which girls or boys can defend their supremacy by an ironic or scornful statement or one which involves a humorous presupposition such as: "when did you stop beating your girlfriend?" 
Another communication skill which should be encouraged involves evading questions which one does not want to answer or cannot answer. The student should be encouraged to meet a question by asking another one, or to shift a question from himself to another person. He can also be encouraged to poke fun at the question. All of these techniques make it easier for a student with a limited knowledge of a language to converse in that language without long and awkward pauses which result from "being at a loss for words."

In summary, the teacher has the opportunity to teach the student the art of getting along in conversation. This art requires much more than a knowledge of the language. It requires the proper frame of mind, which is an open-mindedness toward possible responses. It requires that creativity be rewarded when it is attempted even if the attempt is a clumsy one. It is certainly an art which cannot be practiced with a tape recorder. It belongs in the classroom.

\section{The introduction of new content in communication practice}

An important part of language teaching is the introduction of new vocabulary and grammar material in the classroom. Certain ways of doing this are particularly effective because they take advantage of the teacher's feeling for "the appropriate moment" and his knowledge of the direction the course will take. The principle to be followed is this: certain things will have to be "mastered" in a course, but they should be introduced, as they are needed, in context. "Mastery" can be deferred. The following example illustrating the introduction of a vocabulary item will make this point clear.

If the students have been required to use the new language in situations relevant to their own personal lives, and if they are asked questions which relate to their daily activities, they will quickly need to know how to talk about people other than themselves. Early in a course they might be satisfied to refer to their companions by name and to use words such as boy, or father in order to talk about shared activities. In one text, for example, the word friend is introduced relatively late. In using this text, the word friend is needed long before it is formally introduced. The problem at this point is that a teacher may resist departing from the contents of a text for fear that students will feel overwhelmed by additional vocabulary. The proposed solution is to introduce the new word in the proper context, when it is needed. With the word friend the context and need are usually apparent. 
The word should also be introduced in such a way as not to put pressure on the students to remember it. It may be written on the board so the students can find it easily when they need to use it. The students may be told that they do not have to remember the word, and it is being introduced as a "convenience for the moment." The final step is to return to the word repeatedly whenever it seems particularly appropriate, but never to demand that the students produce it from memory. If the teacher has been careful to introduce a word which he knows will eventually appear in a text, he has insured that there will be a reward for the students when they reach it. It will be so familiar, and the students will feel so comfortable with it, that remembering the word will be no problem. New grammar patterns can be introduced in the same way.

The teacher should see to it that new material is tied into old material whenever possible. In vocabulary this can be done by pointing out that a word means the same thing as, or the opposite of, an old word. In grammar teaching it is particularly important that a new pattern be used in contrast to old patterns. For example, let us see how we could approach the question pattern in English, WHO + VERB + OBJECT ("Who kicked the table?"). It should be introduced with a lexicon which makes it easy to figure out the grammatical relationships within the pattern. In the sentence above, people can kick tables, but tables cannot kick people. Once this is established, the teacher could change the vocabulary to make the meaning of the new question open to two interpretations: "Who hit Bill?" Here, Bill is capable of hitting and being hit, so it may not be clear to the student whether Bill is the object or the subject of the verb. After it is evident that the students thoroughly understand the new pattern, they should be asked to recall a sentence like the following: "Whom did Mary hit?" The two patterns can then be practiced by having Mary actually hit Bill, and following this with a set of questions about the action which has just taken place. Thus both question patterns are used contrastively with relevance to a single situation.

It is a mistake, however, to introduce a new pattern in contrast to an old one with which it might be confused. Many students then worry more about the potential confusion than about the meaning of the new pattern. The need to compare and integrate new patterns with what has come before can be satisfied after the new pattern has acquired some real significance for the students on its own. Thus practice in contrast should follow practice in isolation. The same principle holds true with the introduction of vocabulary. Many students will confuse opposites if they are introduced at the 
same time. To aid these students in remembering, it is best to introduce and practice one member of a natural pair well before the other member is introduced.

\section{The relationship of communication practice to the text and curriculum}

\section{a. Text considerations}

A test can be evaluated from two points of view: usefulness to the student and usefulness to the teacher. The student appreciates a text which will provide him with a clear guide to home study. Many PP texts are satisfactory in this respect since they provide a second, i.e. visual, means of evaluating the correctness of his responses to taped drills. This would require that answers to drills be written in the text. The text is also used as a reference book and should provide an index to the place of introduction of vocabulary in the course. If the language is one which lends itself to a systematic display of grammatical material in the form of paradigms or declensions, then such information can be included. The same can be said of phonology if a special learning alphabet is required. Finally, the text should provide some material in the form of stories or dialogues which introduce the language in a natural way and summarize the new material of each lesson for the student. Thus, (except for one which resembles a computer program or a formal grammar) there are many texts which are satisfactory from the student's point of view.

For the teacher who is interested in CP teaching, a useful text is one which provides a cumulative account of the vocabulary and grammatical patterns presented. A text with this information relieves the teacher of remembering what has been taught before. Then he can easily integrate old material into new patterns. ${ }^{4}$

A text which is effective for $C P$ should introduce all question patterns quickly. The priority for the introduction of grammatical patterns should be based on their usefulness in establishing quick communication rather than on some notion of their relative linguistic difficulty. Early in the course, vocabulary should be introduced which is relevant to the classroom scene (speak, understand, means, repeat, etc.). Surface irregularities such as morphological variants should be introduced gradually so that the burden of remembering them and using them correctly does not make communication difficult. If these priorities are not adhered to, the teacher will observe either or both of the following consequences:

\footnotetext{
${ }^{4}$ For an imaginative description of the nature and function of a corpus, see Fries and Fries (1961), especially Chapters 1 and 2.
} 
1. Students will be able to communicate but incorrectly.

2. Students will be able to manipulate words correctly in drills but not use this manipulation to communicate effectively.

In its format a text must strike a balance between two extremes. The first extreme is one of supplying too many classroom drills, and, in doing so, preventing the drills from being spontaneous and relevant to the class. The second extreme is one of supplying too few drills and leaving the inexperienced teacher without enough material to conduct the class. Perhaps the solution lies in providing two separate texts, one for the student which serves as a guide to home study and as a reference text, and another for the teacher, one which suggests drills to help him through the initial lessons, and also provides a set of sample communication practice drills which will train him to take a more active role in teaching.

A mark of a good teacher is his attitude toward the role of a text and the way he uses it. One virtue of a text is that it exerts a stabilizing force on the course, for the students as well as the teacher. However, when the latter feels that the direction of a text departs from that which leads to effective communication, he should feel free to deviate from the text. He should not feel bound to do every drill, or require memorization of every vocabulary item which is included in the text, since he can judge their appropriateness for his particular class better than the author could when he wrote it.

\section{b. The separation of vocabulary, pronunciation, and grammar classes}

If a course is constructed so that the teacher is restricted to only one aspect of language, such as grammar or pronunciation, then the teacher will be unable to use the full range of techniques at his disposal for stimulating his students. If a teacher is expected to spend an entire class period discussing and drilling phonology, and if he conscientiously does this, he runs a tremendous risk of having the students lose interest and start reacting mechanically. Skill which they acquire in the pronunciation class might have very little carry-over into other classes. This is so because the phonology is not taught as part of a communication system but as an independent sound system.

A student will not learn the significance of developing good pronunciation unless it is stressed outside of the context of a pronunciation drill. If he learns to be aware of phonological mis- 
takes in others' speech at the same time as he is concentrating other things such as meaning, he will be more conscious of his own pronunciation as it affects understanding. If "being understood" is the main criterion for evaluating the adequacy of one's pronunciation, then pronunciation should be emphasized in the classroom whenever it interferes with understanding. The student who associates his own pronunciation habits only with the criticism of a "pronunciation teacher" will completely miss the reason for learning how to pronounce a foreign language adequately-so that he will always be correctly understood.

In relation to an entire language course, pronunciation should be a greater concern in the beginning of the course than later on. Those habits acquired at the start of language study will often be very difficult to change. Thus the teacher should stress pronunciation during the early days of class. But he must also draw attention to, and teach, pronunciation at the same time that he teaches grammar or vocabulary. He will find that doing this is not only necessary but adds variety to his teaching.

Finally, students usually say that given a choice they would rather practice several different skills for short periods of time than practice a single skill for an extended period. If the teacher fails to take advantage of this by not planning each lesson to include a modest amount of new vocabulary, grammar, and phonology, he only shows an insensitivity to the psychology of the student, and his language teaching will suffer as a consequence.

\section{c. The place for pattern practice}

Effective communication involves the development of several skills. The preceding discussion has centered about the teacher's contribution to the development of these skills. There is, however, one skill to which the teacher has little to contribute. This is the skill of producing speech quickly and smoothly. If a student cannot do this, his audience will find it tiring to listen to him. Manipulative skills such as the rapid production of acceptable speech are developed through repetition, evaluation, and more repetition. The pattern practice drill is suitable for this sort of practice since it is a way of eliciting large amounts of controlled vocalization with immediate confirmation, wherein the vocalization is evaluated as to its correctness. Pattern practice drills thus find their proper place in a total language course in the student's practice outside of the classroom.

\section{Conclusion}

Within the total language instruction program, communication practice might be only one of several techniques which the teacher 
could use. However, the principle of teaching students to communicate should underlie the entire program.

Some might argue that teaching communication as I have proposed would be impossible in a large class, but it can be said that it is possible to do very little language teaching at all in a large class. Others might say that the elimination of PP drills from the classroom will result in a class which is more difficult for the teacher to conduct. They will claim that PP drills are easy to construct and administer; however, ease alone is a poor reason for continuing these drills. The results of teaching a language as a medium of vital communication offset the difficulties of administering such a program.

\section{RE FERENCES}

Fries, Charles C., and Agnes C. Fries. 1961. Foundations for English Teaching. Tokyo: Kenkyusha Ltd.

Palmer, Adrian. 1969. A Classroom Technique for Teaching Vocabulary. TESOL Quarterly 2.2. 130-133. 